\title{
A realistic 3-D gated cardiac phantom for quality control of gated myocardial perfusion SPET: the Amsterdam gated (AGATE) cardiac phantom
}

Jacco J. N. Visser ${ }^{1}$, Ellinor Busemann Sokole1, Hein J. Verberne1, Jan B. A. Habraken ${ }^{1}$, Huybert J. F. van de Stadt², Joris E. N. Jaspers², Morgan Shehata², Paul M. Heeman², Berthe L. F. van Eck-Smit ${ }^{1}$

1 Department of Nuclear Medicine, Academic Medical Center, Amsterdam, The Netherlands

2 Department of Medical Technological Development, Academic Medical Center, Amsterdam, The Netherlands

Published online: 8 July 2004

(C) Springer-Verlag 2004

Eur J Nucl Med Mol Imaging (2004) 31:1215-1216

DOI 10.1007/s00259-004-1609-7

\section{Eur J Nucl Med Mol Imaging (2004) 31:222-228}

Owing to technical problems Figs. 1 and 5 were blurred. These figures are now published again below.
Ellinor Busemann Sokole (๘)

Department of Nuclear Medicine, Academic Medical Center, Meibergdreef 9, 1105 AZ Amsterdam, The Netherlands e-mail: e.sokole@amc.uva.nl

Tel.: +31-20-5664550, Fax: +31-20-5669092

The online version of the original article can be found at http://dx.doi.org/10.1007/s00259-003-1352-5

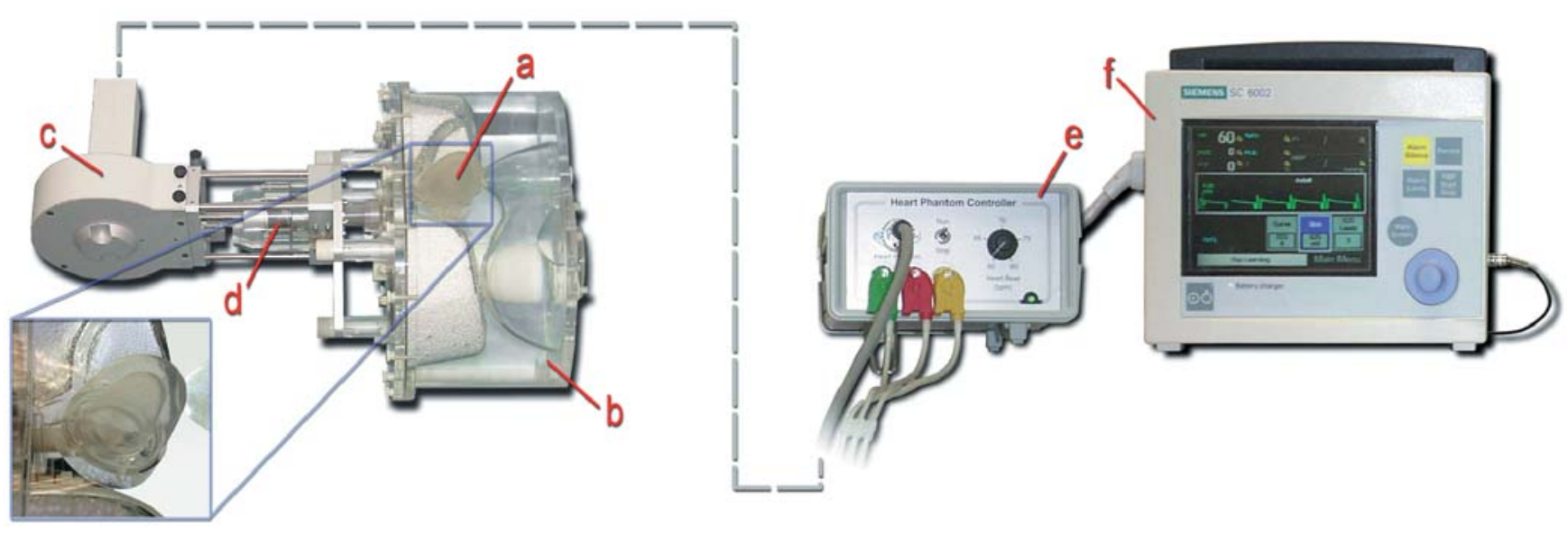

Fig. 1. Elements of the AGATE cardiac phantom: a, left ventricular insert; b, Data Spectrum anthropomorphic torso phantom; c, cam; d, piston; e, phantom controller unit; f, ECG monitor 


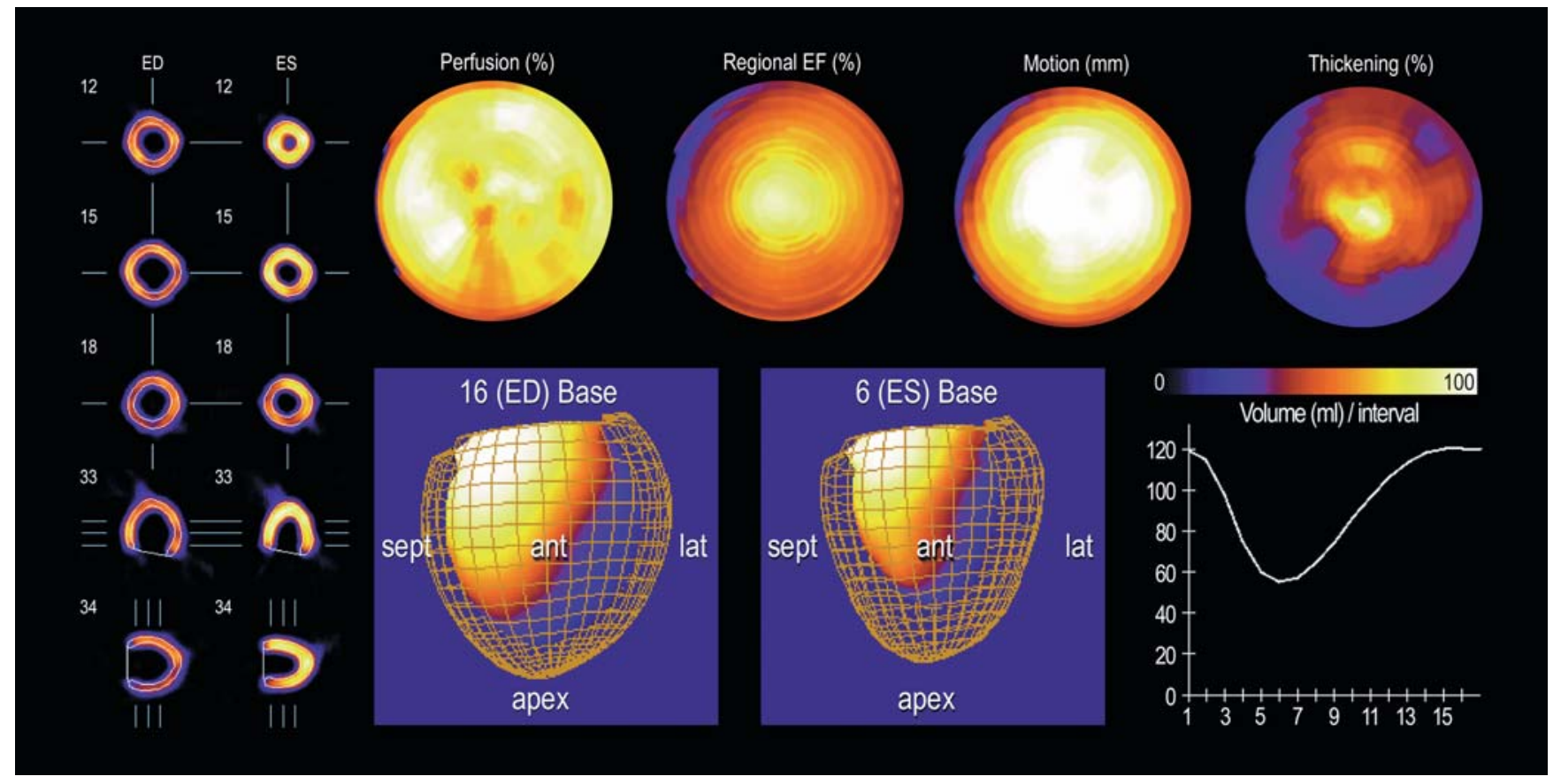

Fig. 5. Results from the QGS quantification software for a 16-frame gated SPET phantom study, showing the tomographic, Bull s eye and volume-rendered images and the stroke volume curve produced 